\title{
RESPONSABILIDADE CIVIL E DANO AMBIENTAL INDIVIDUAL NO DESASTRE DE BRUMADINHO
}

\author{
CIVIL LIABILITY AND INDIVIDUAL ENVIRONMENTAL DAMAGE IN THE BRUMADINHO \\ DISASTER
}

Marcelo Kokke ${ }^{1}$

RESUMO: A responsabilidade civil em matéria ambiental possui efeitos e interligações plurais. A articulação de suas implicações não só permite mas demanda uma contínua via de diálogos entre ramos jurídicos diversos. Direito Ambiental e Direito Civil estão interligados quando se trata do dano ambiental individual. Em situações de desastres ambientais, como o desastre de Brumadinho, as consequências alcançam especial relevância em razão da definição do regime jurídico de responsabilidade. Os bens ambientais não estão vinculados à titularidade, seja pública, seja privada. Entretanto, o regime jurídico dos bens ecológicos projeta efeito na reparação do dano individual ligado ao dano ambiental, especialmente em situações de desastres. $O$ presente artigo propõe articular 0 direito ambiental e o direito civil na identificação de normas aplicáveis a situações de responsabilidade civil. A metodologia utilizada para abordagem é centrada no diálogo das fontes. A partir dessa articulação, sustenta-se em conclusão uma direta influência no sistema de reparação do dano ambiental individual, inclusive quanto ao prazo de prescrição.

Palavras-chave: Responsabilidade civil. Direito Ambiental. Direito Civil. Dano ambiental individual. Desastre de Brumadinho.

\begin{abstract}
Civil liability in the environmental matters has plural effects and interconnections. The articulation of its implications does not allow, the articulation require a continuous mode of dialogues between several legal branches. Environmental law and Civil law are in interconnection when it is about individual environmental damage. In the environmental disaster situations, as Brumadinho's disaster, the consequences reach special relevance in the reason of definition of legal responsibility framework. The environmental goods are not linked to private or public ownership. However, legal framework of ecologic goods projects effects in reparation of individual damage linked to environmental damage, specially, in the disaster situations. This paper proposes makes articulation between environmental law and civil law in order to identify applicable legal standards to civil liability situations. In order to get it, the approach is based in methodology of the dialogue of sources. As from this articulation, the paper supports the conclusion of a direct influence in the reparation system of individual environmental damage, including limitation period to claim.
\end{abstract}

Keywords: Environmental law. Civil law. Individual environmental damage. Brumadinho disaster.

\footnotetext{
${ }^{1}$ Pós-doutor em Direito Público - Ambiental pela Universidade de Santiago de Compostela - ES. Mestre e Doutor em Direito pela PUC-Rio. Especialista em processo constitucional. Pós-graduação em Ecologia e Monitoramento Ambiental. Procurador Federal da Advocacia-Geral da União. Núcleo Especializado em Ambiental e ações prioritárias da Procuradoria Federal no Estado de Minas Gerais. Professor de Direito da Escola Superior Dom Helder Câmara. Professor de Pós-graduação da PUC-MG. Professor colaborador da Escola da Advocacia-Geral da União. E-mail: marcelokokke@yahoo.com.br
} 


\section{Revista IBERC}

v.2, n. 1, p. 01-16, jan.-abr./2019

www.responsabilidadecivil.org

Sumário: 1. Introdução. 2. Bens privados e danos socioambientais em desastres. 3. Prescrição para reparação de danos individuais em desastres. 4. Considerações finais. 5. Referências.

\section{INTRODUÇÃO}

A responsabilidade civil em matéria ambiental possui efeitos e interligações plurais. A articulação de suas implicações não só permite mas demanda uma contínua via de diálogos entre ramos jurídicos diversos. Em situações de desastres socioambientais e ambientais propriamente ditos, a articulação para a definição da responsabilidade civil atinge tons ainda mais concentrados e exigentes. Definir como o regime jurídico do dano ambiental afeta a reparação dos danos individuais exige ultrapassar fronteiras estáticas entre os ramos jurídicos. É preciso superar estigmas pertinentes a quadros de aplicação normativa que não mais se mostram adequados à dinâmica da sociedade de risco, ${ }^{2}$ quando se manifestam desastres ambientais e socioambientais. Aplica-se aqui a ideia de Marcelo Abelha Rodrigues ao tratar dos megaconflitos como marca da sociedade de massas, na qual há "um zigue zague de interesses individuais e coletivos em todas as direções, conectados entre si formando uma teia complexa de relações jurídicas". ${ }^{3}$

O desastre socioambiental não é uma mera locução verbal, é uma categoria jurídica que determina a abertura para aplicação de normas e regência de relações emergenciais e reconstrutivas em face da proporção que determinados danos alcançam nas relações humanas para com o ambiente. Seja no caso de desastres antropogênicos, seja no caso de desastres propriamente naturais, o que se tem em conta é uma fronteira cada vez mais cinzenta, dada a direta participação humana seja na ocorrência do evento, seja no grau de suas produções de efeitos.

O presente artigo pretende tematizar as interligações entre o Direito Ambiental e o Direito Civil em matéria de responsabilidade civil decorrente de danos ambientais. Os danos ambientais, sejam eles ou não ligados a desastres ambientais, podem apresentar-se como afetos a bens simultaneamente públicos e privados em sua relevância. Lado outro, eventos ambientais nocivos podem derivar impacto patrimonial e extrapatrimonial em direitos individuais. Os desastres ambientais, particularmente mostram-se em dupla face trágica. Se, de um lado, seus efeitos são

\footnotetext{
2 "Así pues, para hacer frente a los peligros generados por las actividades humanas, 'la sociedad de riesgo' necesita urgentemente cambiar su forma de pensar o concebir la naturaleza, para que su visión eminentemente antropocéntrica, sea sustituida por una concepción biocéntrica, en la cual los males cometidos contra la naturaleza sean vistos como males que afectarán a los seres humanos." (LANCHOTTI, Andressa de Oliveira. Evaluación de impacto ambiental y desarrollo sostenible. Belo Horizonte: Arraes, 2014, p. 244).

${ }^{3}$ RODRIGUES, Marcelo Abelha. Fundamentos da tutela coletiva. Brasília: Gazeta Jurídica, 2017, p. 69.
}

Revista IBERC, Minas Gerais, v.2, n.1, p. 01-16, jan.-abr./2019 


\section{Revista IBERC}

v.2, n. 1, p. 01-16, jan.-abr./2019

www.responsabilidadecivil.org

nefastos para a sociedade como um todo, de outro, seus efeitos são deletérios para a vida dos direta ou indiretamente atingidos.

O desastre socioambiental de Brumadinho é emblemático nesses aspectos. A plena dimensão do desastre ainda não está plenamente delimitada, mas é possível sintetizar, em um quadro pintado após vinte dias de sua ocorrência, o cenário vivenciado. No dia 25 de janeiro de 2019, no município de Brumadinho, em Minas Gerais, a Barragem B 1 - Mina do Feijão, sob responsabilidade da empresa Vale S.A., veio a romper-se. A área total da barragem era de cerca de 27 hectares, possuindo oitenta e sete metros de altura. Embora a barragem não estivesse em operação desde o ano de 2016, ela já estava em processo de descomissionamento. O volume de rejeitos dispostos na barragem era de aproximadamente 12 milhões de metros cúbicos de minério de ferro.

O colapso da barragem resultou em centenas de pessoas soterradas vivas, contando-se, quando da elaboração deste trabalho, 165 mortos e mais de 160 desaparecidos, centenas de desabrigados e milhares de afetados em suas propriedades e economia. A área inundada com os rejeitos ainda está em delimitação, tendo ocorrido contaminação da bacia hidrográfica do Paraopeba, em Minas Gerais, inserta na bacia do rio São Francisco. Os danos humanitários e ecológicos são imensuráveis.

Os desastres socioambientais afetam tanto bens ambientais propriamente ditos quanto bens individuais que são comprometidos pela ocorrência destrutiva. Mas os efeitos destrutivos, apesar de se apresentarem em conjunturas de titularidade diferentes, apresentarão pontos de comunicação em seu regime de tratamento jurídico. Aqui se situa a base argumentativa de consubstanciação do denominado dano ambiental individual. O diagnóstico e avaliação dos danos socioambientais produzidos em função de um desastre ambiental de causa antrópica determinam comunicância de institutos jurídicos e de um regime jurídico comum, que irá impactar na definição de normas jurídicas e marcos para os prazos prescricionais.

Em que medida um dano ambiental individual possui especificidade em aspectos de prescrição para sua reparação? Como se rege a prescrição para reparação do dano ambiental quando um mesmo ato desempenhe efeitos negativos ao bem ambiental propriamente dito e a direitos individuais, seja em ângulo patrimonial, seja em ângulo extrapatrimonial? Em que medida uma infração ambiental e uma lesão ao patrimônio individual podem se sobrepor? É possível afirmar que, no caso do desastre socioambiental de Brumadinho, o início do prazo prescricional para reparação dos atingidos ocorre com a ocorrência em si do desastre?

Para enfrentamento dos problemas propostos, assume-se uma base metodológica centrada no diálogo das fontes, com ênfase na comunicatividade e entrelaçamento de ramos jurídicos. A hipótese que se pretende demonstrar como a mais apta e sustentável para 


\section{Revista IBERC}

v.2, n. 1, p. 01-16, jan.-abr./2019

www.responsabilidadecivil.org

responder à pergunta passa por uma delimitação entre os efeitos da lesão ao bem ambiental em suas diversas conformações de apresentação social. Essas conformações são distinguíveis, mas também enlaçadas, principalmente quando se busca a reparação em situações de desastres. Em abordagem direta, pretende-se por meio do diálogo de fontes sustentar diversidade de regimes prescricionais, mas com interferências entre eles em situações de exercício do direito de ação.

\section{BENS PRIVADOS E DANOS SOCIOAMBIENTAIS EM DESASTRES}

A limitação da classificação dos bens em públicos e privados fica clarividente quando se toma em conta os bens ambientais. O caráter de bem ambiental não advém da propriedade, não tem lastro com a titularidade. A caracterização como bem ambiental advém da especial função exercida pelo bem em um cenário coletivo de implicações. Considerando os diversos prismas em que é classificado o meio ambiente, natural, artificial, cultural, do trabalho ou virtual, os componentes bióticos e abióticos interagem em um fluxo pulsante.

Não há linhas de propriedade, no sentido dominial, que sejam compatíveis com a dinâmica do fluxo pulsante próprio da função ecológica. As propriedades de diversos indivíduos podem assim se interligar ou interagir para integrar uma cadeia de relações ecológicas. Igualmente, um dano provocado a bens ecológicos repercute social e economicamente, desencadeando prejuízos privados diretamente emergentes da lesão sofrida pelo meio ambiente. No cenário dos desastres, a situação é ainda mais clarividente. Desastres antropogênicos não resultam somente em efeitos deletérios para funções ecológicas desempenhadas por determinados bens, resultam também em prejuízos de sustentabilidade com repercussão direta em meios de vida e equilíbrio econômico-social da coletividade e das comunidades que a compõem.

Por essa razão, ao tutelar os bens ambientais, o artigo 225 da Constituição da República determina como direito difuso, ali referido como bem comum do povo, o meio ambiente ecologicamente equilibrado. Essa proteção pressupõe ofensiva ativa em favor da preservação e restauração dos processos ecológicos essenciais e provimento do manejo ecológico das espécies e ecossistemas. Mas essa preservação não significa extirpar da avaliação de equilíbrio o papel humano, pelo contrário, a relação entre ser humano e ecossistema é imprescindível na avaliação do real equilíbrio ecológico. Desta forma, em ocorrências de desastre socioambiental,

Revista IBERC, Minas Gerais, v.2, n.1, p. 01-16, jan.-abr./2019 


\title{
Revista IBERC
}

v.2, n. 1, p. 01-16, jan.-abr./2019

www.responsabilidadecivil.org

a perturbação do meio ambiente compreende tanto a perturbação de processos ecológicos propriamente ditos quanto a perturbação deletéria das relações de integração humana no ambiente afetado.

A tutela jurídica das interações tróficas e equilíbrio em homeorese, ${ }^{4}$ nos planos ecológicos propriamente ditos, desde populações até a dinâmica de biomas, inclusive erigida como pilar na Convenção de Diversidade Biológica, é ponto de leitura e interpretação na aplicação do Direito Ambiental. Mas, e quando a avaliação das componentes bióticas e abióticas se enlaça com o direito de propriedade e com as relações econômico-sociais desenvolvidas na interrelação com o ambiente? Esta última fica comprometida tanto com a denominada função socioambiental da propriedade como com a função ecológica. Enquanto a primeira está relacionada com o uso sustentável da propriedade, a segunda diz respeito à preservação e restauração de processos ecológicos que envolvem a ecologia da paisagem. Os prismas da ecologia da paisagem são assim capitulados por Jean Paul Metzger:

\begin{abstract}
As definições de ecologia de paisagens variam em função da abordagem ("geográfica" ou "ecológica") e dos autores. A ecologia de paisagens é entendida como: o estudo da estrutura, função e dinâmica de áreas heterogêneas compostas por ecossistemas interativos (Forman \& Godron 1986); a investigação da estrutura e funcionamento de ecossistemas na escala da paisagem (Pojar et al. 1994); uma área de conhecimento que dá ênfase às escalas espaciais amplas e aos efeitos ecológicos do padrão de distribuição espacial dos ecossistemas (Turner 1989); uma forma de considerar a heterogeneidade ambiental em termos espacialmente explícitos (Wiens et al. 1993); uma área de conhecimento que considera o desenvolvimento e a dinâmica da heterogeneidade espacial, as interações e trocas espaciais e temporais através de paisagens heterogêneas, as influências da heterogeneidade espacial nos processos bióticos e abióticos e o manejo da heterogeneidade espacial (Risser et al. 1984); uma ciência interdisciplinar que lida com as interações entre a sociedade humana e seu espaço de vida, natural e construído (Naveh \& Lieberman 1994). ${ }^{5}$
\end{abstract}

Diversas propriedades ou bens de titularidade pública ou privada podem estar envolvidos em um mesmo panorama de paisagem, pertencer ao mesmo complexo de interação biótica. $O$ desastre socioambiental é evento de perturbação e aniquilação do equilíbrio então estabelecido. Uma de suas principais características é a degradação da conjuntura de paisagem estabelecida. As imagens de destruição presentes no desastre de Brumadinho, assim como no de Mariana, ${ }^{6}$

\footnotetext{
${ }^{4}$ ODUM, Eugene P.; BARRET, Gary W. Fundamentos de ecologia. Trad. Pégasus Sistemas e Soluções. São Paulo: Cengage Learning, 2017. Título original: Fundamentals of ecology.

${ }^{5}$ METZGER, Jean Paul. O que é ecologia de paisagens? Biota Neotropica, Campinas/SP, vol. 1, n. 1/2, 2001 , p. 1-9, p. 3.

${ }^{6}$ Aplicam-se aqui as enfáticas e fundamentadas críticas desenvolvidas por Nelson Rosenvald ao modelo exploratório minerário brasileiro, inclusive em razão de mecanismos de desvio de responsabilidade a partir
} 


\section{Revista IBERC}

v.2, n. 1, p. 01-16, jan.-abr./2019

www.responsabilidadecivil.org

também ocorrido em Minas Gerais, possuem uma significação direta em termos de colapso dos elementos bióticos e abióticos que se estabeleceram no ecossistema. Em outras palavras, quando se tem a projeção dos rejeitos de mineração sobre vida humana e não humana, assim como sobre espaços físicos em que se tinha determinada conformação abiótica, desestrutura-se, desfuncionaliza-se, aniquila-se a dinâmica recíproca entre ecossistemas interativos.

O desastre atinge tanto os bens privados propriamente ditos quanto as diversas composições de função ecológica presentes em dado ecossistema. Um mesmo ato ilícito possui repercussão na propriedade, no direito individual, e repercussão negativa nos bens ambientais, esta última em caráter difuso de afetação. Embora o Direito se esforce por conceber linhas de delimitação, ecologicamente isso não é possível. A cadeia de reflexos é consequencial justamente porque seres vivos, humanos e não humanos, processos econômicos e relações sociais, passam-se em cenários ambientais, passam-se a partir dos níveis de conformação do ecossistema.

É comum em sede de jurisprudência dos Tribunais asseverar-se que há independência entre a responsabilidade civil, a penal e a administrativa em matéria ambiental. Mas há também tipo de interdependência outra pouco abordada. Há uma interdependência entre danos ambientais com efeitos difusos e o denominado dano ambiental individual. $\mathrm{O}$ dano ambiental individual $^{7}$, como o próprio nome indica, está implicado ao dano que atinge direitos individuais, seja em escala patrimonial, seja em escala extrapatrimonial, mas que se materializa com prejuízo ao meio ambiente. Há, nesses trilhos, uma junção íntima entre o dano ambiental individual e o dano ambiental em sua performance difusa de irradiação de efeitos, implicada inclusive pelo valor social do bem ambiental. ${ }^{8} \mathrm{O}$ desastre socioambiental é uma fonte simultânea de destruição que afeta tanto o ecossistema em sua expressão de titularidade difusa quanto as propriedades e relações econômico-sociais pessoais que se passam em seu interior.

O manejo dessa interligação não se produz sem um suporte, sem uma base teórica de sustentação. E esta base pode ser situada no diálogo das fontes. A teoria do diálogo das fontes concentra atenções em uma necessária construção interativa de normas jurídicas a partir de interlocuções de diplomas de diversos âmbitos ou ramos jurídicos. Relações jurídicas privadas, ou decorrentes de ramos reconhecidos comumente como de direito privado, são implicadas e

da criação de "centros autônomos de imputação jurídica" (ROSENVALD, Nelson. O direito civil em movimento: desafios contemporâneos. 2. ed. Salvador: Editora JusPodivm, 2018, p. 225).

7 LEITE, José Rubens Morato; AYALA, Patrick de Araújo. Dano ambiental: do individual ao coletivo extrapatrimonial: teoria e prática. 5. ed. São Paulo: Editora Revista dos Tribunais, 2012, p. 147.

${ }^{8}$ SIQUEIRA, Lyssandro Norton. Qual o valor do meio ambiente? Previsão normativa de parâmetros para a valoração econômica do bem natural impactado pela atividade minerária. Rio de Janeiro: Lumen Juris, 2017. 


\section{Revista IBERC}

v.2, n. 1, p. 01-16, jan.-abr./2019

www.responsabilidadecivil.org

entram em diálogo com ramos jurídicos tidos como de direito público para daí extraírem interpretações conciliadoras e de otimização em eficácia das previsões reguladoras. ${ }^{9}$

Jayme,$^{10}$ salientando um dever de evitar contradições, visa justamente argumentar contra fragmentações, contra pretensões interpretativas que estanquem as normas jurídicas e Ihes retire a eficácia, ou mesmo recaiam em interpretações desvinculadas com os padrões de realidade a que se destinam em aplicação. A partir do diálogo das fontes, não se pode pensar em normas de direito privado, em normas civilísticas para regramento da propriedade ou mesmo da responsabilidade civil por dano a direitos individuais, sem ter em consideração a interlocução e presença comunicativa das normas de direito ambiental.

As normas ambientais implicam assim efeitos diretos nas normas civis. A responsabilidade civil por dano à propriedade é implicada de efeitos diretos se o dano é a um bem ambiental. Essa interlocução é maximizada em casos de desastres, afinal, aqui se realiza a hipótese de catástrofe abstratamente entendida em uma sociedade de risco, aqui o conhecimento do risco de eventos extremos reflete na régua de aferição do dever de proteção e da responsabilidade civil em face do dano. ${ }^{11}$

Disso resulta, pelo diálogo das fontes, que os danos e lesões sofridos pelas vítimas do desastre socioambiental de Brumadinho não tem centrada apenas nas normas de direito privado sua tutela jurídica para afirmação da responsabilidade civil do causador do dano. A tutela jurídica das vítimas se faz também pelas normas do direito ambiental, mais, a tutela jurídica é estabelecida com aplicação direta de princípios e institutos próprios da responsabilidade civil por dano ambiental. A conexão entre os âmbitos jurídicos proporciona uma integração que afeta processual e materialmente a postulação de reparação da lesão sofrida.

O dano econômico-social sofrido por alguém em virtude de um desastre socioambiental desencadeia a caracterização da lesão como dano ambiental individual. $\mathrm{O}$ dano à propriedade, $\mathrm{O}$ dano moral sofrido pelos atingidos, implica-se em situação fática diretamente com o dano aos processos ecológicos e à desconformação da paisagem em que se integrava o equilíbrio da vida social. Portanto, no dano ambiental individual, "a demanda tem como base um interesse próprio do indivíduo ao microbem ambiental e que, de forma incidental, repercute na proteção do macrobem ambiental pertencente à coletividade". ${ }^{2}$ A interligação entre o dano ao meio

\footnotetext{
9 JAYME, Erik. Direito Internacional Privado e Cultura Pós-Moderna (1996). Cadernos do Programa de PósGraduação em Direito - PPGDir./UFRGS, Porto Alegre, v. 1, n. 1, nov. 2003. ISSN 2317-8558. Disponível em: http://seer.ufrgs.br/index.php/ppgdir/article/view/43487/27366. Acesso em: 01 ago. 2018. doi:https://doi.org/10.22456/2317-8558.43487, p. 44.

10 JAYME, Erik. Direito Internacional Privado..., p. 109.

${ }^{11}$ CARVALHO, Délton Winter de. Desastres ambientais e sua regulação jurídica: deveres de prevenção, resposta e compensação ambiental. São Paulo: Editora Revista dos Tribunais, 2015, p. 162.

12 LEITE, José Rubens Morato; AYALA, Patrick de Araújo. Dano ambiental..., p. 150.
} 


\section{Revista IBERC}

v.2, n. 1, p. 01-16, jan.-abr./2019

www.responsabilidadecivil.org

ambiente, principalmente em sua feição ecológica, e o dano a direitos individuais proporciona uma releitura de normas privatistas.

A relação de interdependência é expressada pelo diferenciado regime jurídico de imputação. O dano patrimonial assume caráter de disponibilidade, ao inverso do dano ambiental ou ecológico. Assim, em situações em que a propriedade ou outro direito individual seja lesado, é possível inclusive acordos e transações para que a obrigação de fazer seja convertida em perdas e danos sem que isso implique qualquer efeito em termos ambientais. Dessa forma, mesmo havendo a composição privada quanto ao pagamento de perdas e danos, ainda será devida a obrigação ambiental de reparação integral, restaurando ou recuperando a área degradada.

No exemplo citado, mesmo se a pessoa física ou jurídica aceitar indenização em razão do dano patrimonial sofrido, ainda restará o dano provocado ao processo ecológico, determinando assim a necessária reparação do equilíbrio ecossistêmico. Nessa linha, Annelise Monteiro Steigleder pondera que "embora seja reconhecido o dano ecológico puro, o seu ressarcimento não é dissociado dos danos individuais". ${ }^{13}$ Há uma independência relativa, portanto, entre a reparação de danos pessoais, patrimoniais, morais ou econômicos decorrentes do desastre e os danos ecológicos, mas esta interferência permite também que aspectos de prova, configuração e actio nata influenciem no manejo e prazo prescricional das ações privadas.

Se a reparação do dano pode remeter tanto ao ecológico quanto ao dano a direito individual, construídos em um mesmo suporte fático de ocorrência lesiva, é possível sustentar amplo ao suporte normativo, para além das regras de direito privado, e elastecimento do próprio regime jurídico de reparação. Tanto Steigleder ${ }^{14}$ quanto Morato Leite e Patryck Ayala ${ }^{15}$ sustentam, e com razão, a possibilidade de normas ambientais e mesmo processuais ambientais ampararem demandas privadas que repercutam em tutela de processos ecológicos. A proteção do bem privado, a reparação de danos patrimoniais e morais, amarra a responsabilidade civil do causador com patamares legais próprios da responsabilidade ambiental. Nesse sentido, Délton Winter de Carvalho é incisivo ao firmar que "resta claro que a ressarcibilidade do dano ambiental individual e a incidência da responsabilidade civil objetiva"16 do causador do dano ambiental individual.

Portanto, os atingidos direta ou indiretamente no desastre ambiental de Brumadinho podem postular a responsabilidade da empresa causadora como uma responsabilidade objetiva,

\footnotetext{
${ }^{13}$ STEIGLEDER, Annelise Monteiro. Responsabilidade civil ambiental: as dimensões do dano ambiental no direito brasileiro. Porto Alegre: Livraria do Advogado Editora, 2017, p. 56.

${ }^{14}$ STEIGLEDER, Annelise Monteiro. Responsabilidade civil ambiental..., p. 55-56.

${ }^{15}$ LEITE, José Rubens Morato; AYALA, Patrick de Araújo. Dano ambiental..., p. 150-151.

${ }^{16}$ CARVALHO, Délton Winter de. Dano ambiental futuro: a responsabilização civil pelo risco ambiental. Porto Alegre: Livraria do Advogado, 2013, p. 112.
} 


\section{Revista IBERC}

v.2, n. 1, p. 01-16, jan.-abr./2019

www.responsabilidadecivil.org

independentemente de culpa. Além disso, é possível à pessoa lesada em seu patrimônio valerse de normas ambientais, tal como a Lei n. 6.938/81, que trata da Política Nacional do Meio Ambiente, para buscar a reparação patrimonial do bem que seja qualificado como bem ambiental. As consequências não são diminutas. O manejo processual implica efeitos inclusive para além da responsabilidade objetiva. Se a lesão provocada no patrimônio individual for coincidente com a lesão ambiental, ou seja, se a reparação do bem ambiental coincidir com a reparação do bem privado, o tipo de responsabilidade civil objetiva enlaçado ao processo será modificado.

Explicitamente, aplicando-se à reparação do dano ambiental oriundo de desastre antropogênico a responsabilidade objetiva pela teoria do risco integral, a reparação postulada na ação privada de reparação patrimonial ou extrapatrimonial poderá dela se valer. Desta forma, se em um processo comum a responsabilização dependeria da prova de culpa, ao haver coincidência e superposição do direito individual pelo direito difuso ao meio ambiente, o bem privado é recoberto pela qualificação de bem ambiental. Será patente a aplicação da responsabilidade objetiva, prescindindo-se da culpa.

Mas mais do que isso, se a dimensão da responsabilidade objetiva admite a possibilidade de força maior ou caso fortuito para sua exclusão, isso não ocorrerá no caso de dano ambiental individual. A teoria do risco integral se aplica. Portanto, em caso de desastre socioambiental antropogênico, seja para o dano ecológico, seja para o dano ambiental individual, a responsabilidade é objetiva e infensa às excludentes de responsabilidade.

A questão afeta também o próprio nexo de causalidade. $O$ dano ambiental implica atração de princípios como a prevenção e precaução. O Superior Tribunal de Justiça firmou posicionamento no sentido de que ambos os princípios permitem a inversão do ônus da prova na relação de causalidade entre a omissão ou ação e o dano provocado. O STJ explicita, em seu repertório de Jurisprudência em Teses, n. 30, que "o princípio da precaução pressupõe a inversão do ônus probatório, competindo a quem supostamente promoveu o dano ambiental comprovar que não o causou ou que a substância lançada ao meio ambiente não the é potencialmente lesiva"17.

Seguindo o diálogo das fontes, se o dano ambiental for coincidente com o dano pessoal patrimonial ou extrapatrimonial, ou seja, se o dano ambiental individual for configurado em uma concomitante demonstração de produção de lesividade a processos ecológicos ou contornos de

\footnotetext{
${ }^{17}$ STJ. Segunda Turma. REsp n. 1237893/SP, Rel. Ministra Eliana Calmon, julgado em 24/09/2013, DJE 01/10/2013. STJ. Terceira Turma. AgRg no AREsp 206748/SP, Rel. Ministro Ricardo Villas Bôas Cueva, julgado em 21/02/2013, DJE 27/02/2013.

Todos os acórdãos proferidos pelo Superior Tribunal de Justiça, mencionados neste artigo, estão disponíveis em: www.stj.jus.br.
}

Revista IBERC, Minas Gerais, v.2, n.1, p. 01-16, jan.-abr./2019 


\section{Revista IBERC}

v.2, n. 1, p. 01-16, jan.-abr./2019

www.responsabilidadecivil.org

funcionalidade ambiental do bem, é possível, mesmo em demandas privadas, a aplicação dos princípios ambientais da precaução e prevenção para postular a inversão do ônus da prova. $A$ dinâmica processual da reparação do dano, em uma ação privada, altera-se substancialmente inclusive para demonstrar a extensão das perdas sofridas pelos atingidos.

Mas a questão que sobrevém e gera incógnita diz respeito ao prazo para postulação da reparação. Como se rege o prazo para as vítimas do dano decorrente do desastre de Brumadinho pleitearem sua reparação? A demanda para reparação dos bens ambientais e a demanda para reparação por responsabilidade civil em escala individual implicam regimes jurídicos diversos. A interdependência, a comunicatividade, é desta forma afetada em outro prisma, o prisma da prescrição para pretensão da reparação dos danos.

\section{PRESCRIÇÃO PARA REPARAÇÃO DE DANOS INDIVIDUAIS EM DESASTRES}

O exercício do direito de ação em situações de dano ambiental possui diversidade de regimes jurídicos. O dano ambiental propriamente dito, também denominado como dano ecológico, está intrincadamente ligado ao caráter intergeracional de relevância do meio ambiente. A responsabilidade civil por danos ao meio ambiente, ao viés de se tratar de responsabilização por violação de um direito difuso, cujo efeito se projeta na geração presente $e$ nas gerações futuras, é qualificada pelo Superior Tribunal de Justiça como sujeita à pretensão de reparação imprescritível. A lógica se aplica com ainda maior potência em casos de desastres ambientais.

A posição é bastante sólida em esfera judicial: "é imprescritível a pretensão reparatória de danos ambientais, na esteira de reiterada jurisprudência deste Superior Tribunal de Justiça" (AgRg no REsp 1.466.096/RS, Rel. Ministro Mauro; Campbell Marques, Segunda Turma, DJe 30/3/2015; AgRg no REsp 1.150.479/RS, Rel. Ministro Humberto Martins, Segunda Turma, DJe 14/10/2011). Os danos ambientais, portanto, não estão sujeitos a qualquer prazo para que seja postulada a reparação lesiva.

Por outro lado, a responsabilidade civil em esfera privada, quando afeta direitos individuais, é expressamente sujeita à prescrição. O Código Civil dispõe em seu artigo 206, $3^{\circ}$, inciso $\mathrm{V}$, que prescreve em três anos o direito de ação para postular a reparação por danos decorrentes de responsabilidade civil. Não há aqui exceção para danos ocorridos em situações de desastres ambientais. Os danos ocorridos a partir do desastre socioambiental de Brumadinho são sujeitos a prazo prescricional.

Revista IBERC, Minas Gerais, v.2, n.1, p. 01-16, jan.-abr./2019 


\section{Revista IBERC}

v.2, n. 1, p. 01-16, jan.-abr./2019

www.responsabilidadecivil.org

O Superior Tribunal de Justiça possui interpretação ampla do dispositivo, tendo afirmado que "o termo 'reparação civil', constante do art. 206, § $3^{\circ}$, V, do CC/2002, deve ser interpretado de maneira ampla, alcançando tanto a responsabilidade contratual (arts. 389 a 405) como a extracontratual (arts. 927 a 954), ainda que decorrente de dano exclusivamente moral (art. 186, parte final), e o abuso de direito (art. 187). Assim, a prescrição das pretensões dessa natureza originadas sob a égide do novo paradigma do Código Civil de 2002 deve observar o prazo comum de três anos. Ficam ressalvadas as pretensões cujos prazos prescricionais estão estabelecidos em disposições legais especiais" (REsp 1.281.594/SP, Rel. Ministro Marco Aurélio Bellizze, Terceira Turma, j. 22/11/2016, DJe 28/11/2016). Nessa última hipótese, tem-se a situação de um dano ambiental que seja também oriundo de relação de consumo, quando então o prazo é elastecido para cinco anos.

$\mathrm{Na}$ linha jurisprudencial firmada, em casos de responsabilidade civil, patrimonial e extrapatrimonial, independentemente da qualidade revestida pelo bem, o prazo prescricional é de três anos. Via de consequência, mesmo em se tratando de danos qualificados como dano ambiental individual, perduraria o prazo de prescrição de três anos. Eventual argumentação da imprescritibilidade em relação a danos individuais, mesmo que tenha vinculação a um bem privado que exerça função ecológica, é frágil, pois olvida que o caráter intergeracional e fundado na dimensão difusa do dano é o núcleo que arregimenta a imprescritibilidade do dano ambiental propriamente dito.

Não se pode confundir o dano em seu caráter ambiental difuso para com os prejuízos privados dele advindos, inclusive em situações de desastres. As vias processuais de tutela de direitos difusos não podem ser contornadas para que a proteção ecológica atue como via de superação da prescrição em uma pretensão de tutela de direito privado. Aqui há o limite para o exercício do diálogo das fontes. O diálogo não significa hibridismo de institutos, afinal, a tese viria a consagrar um direito privado imprescritível.

Há que se ponderar, entretanto, que o delineamento da extensão da imprescritibilidade em matéria ambiental ainda está em julgamento pelo Supremo Tribunal Federal, em sede de repercussão geral (Tema 999), decorrente do Recurso Extraordinário n. $654833^{18}$. A postulação junto ao Supremo consiste em que se delimite tanto a constitucionalidade da imprescritibilidade em si, quanto sua aplicação a fatos ocorridos anteriormente à Constituição da República, tal qual em que termos e limites ocorreria a imprescritibilidade. Afinal, por exemplo, pretensões de dano

\footnotetext{
${ }^{18}$ STF. Tema n. 999. Imprescritibilidade da pretensão de reparação civil de dano ambiental. Relator Min. Alexandre de Moraes. Leading Case: RE n. 654833. Disponível em: http://www.stf.jus.br/portal/jurisprudenciaRepercussao/verAndamentoProcesso.asp?incidente $=4130104 \& \mathrm{nu}$ meroProcesso $=654833 \&$ classeProcesso $=$ RE\&numeroTema $=999$.
}

Revista IBERC, Minas Gerais, v.2, n.1, p. 01-16, jan.-abr./2019 


\section{Revista IBERC}

v.2, n. 1, p. 01-16, jan.-abr./2019

www.responsabilidadecivil.org

moral coletivo em matéria ambiental não se qualificam propriamente como reparação por dano ambiental.

No julgamento que reconheceu a existência de repercussão geral da questão constitucional suscitada, há expressa referência à decisão do Superior Tribunal de Justiça, ao REsp 1.120.117/AC. Neste último, o Superior Tribunal de Justiça firmou pela duplicidade de caminhos. Há fluxo prescricional para a pretensão de reparação de danos individuais decorrentes da lesão ambiental, embora não haja prescrição de reparação do dano ambiental propriamente dito.

(...)

3. Reparação pelos danos materiais e morais, consubstanciados na extração ilegal de madeira da área indígena.

4. O dano ambiental além de atingir de imediato o bem jurídico que lhe está próximo, a comunidade indígena, também atinge a todos os integrantes do Estado, espraiando-se para toda a comunidade local, não indígena e para futuras gerações pela irreversibilidade do mal ocasionado.

5. Tratando-se de direito difuso, a reparação civil assume grande amplitude, com profundas implicações na espécie de responsabilidade do degradador que é objetiva, fundada no simples risco ou no simples fato da atividade danosa, independentemente da culpa do agente causador do dano.

6. O direito ao pedido de reparação de danos ambientais, dentro da logicidade hermenêutica, está protegido pelo manto da imprescritibilidade, por se tratar de direito inerente à vida, fundamental e essencial à afirmação dos povos, independentemente de não estar expresso em texto legal.

7. Em matéria de prescrição cumpre distinguir qual o bem jurídico tutelado: se eminentemente privado seguem-se os prazos normais das ações indenizatórias; se o bem jurídico é indisponível, fundamental, antecedendo a todos os demais direitos, pois sem ele não há vida, nem saúde, nem trabalho, nem lazer, considera-se imprescritível o direito à reparação.

8. O dano ambiental inclui-se dentre os direitos indisponíveis e como tal está dentre os poucos acobertados pelo manto da imprescritibilidade a ação que visa reparar o dano ambiental.

$(\ldots)^{19}$

A linha que se consolida no ordenamento jurídico brasileiro, no que tange à prescrição, é de distinção entre o dano ambiental propriamente dito e os danos individuais interligados à lesão ao meio ambiente. Passado o prazo de três anos, a reparação por dano ambiental em esferas privadas, seja patrimonial ou extrapatrimonial, ainda pode ser demandada, mas restritamente aos aspectos ecológicos, em razão de seu caráter difuso de afetação.

Embora haja limites e diferenciações quanto à sujeição à prescrição, isso não significa ausência de liames de impacto no ajuizamento de demandas voltadas para a reparação de danos ecológicos ou ambientais sobre eventual exercício de ação voltado para a tutela de direitos individuais interligados aos bens afetados. Em outras palavras, as ações judiciais de

\footnotetext{
${ }^{19}$ STJ. Segunda Turma. REsp n. 1120117/AC, Rel. Ministra Eliana Calmon, julgado em 10/11/2009, DJe 19/11/2009.
} 


\section{Revista IBERC}

v.2, n. 1, p. 01-16, jan.-abr./2019

www.responsabilidadecivil.org

escala difusa ou coletiva que visem repercutir na reparação dos danos aos processos ecológicos derivados do desastre socioambiental irão interferir na dinâmica das ações privadas de reparação.

O diálogo das fontes determinará nesse ponto concentração de atenções sobre o dano, escalando em relevo o patamar desencadeador de verdadeira actio nata. Não será a data em si do desastre de Brumadinho o marco para o prazo prescricional de reparação por danos ambientais individuais. Somente a partir do momento em que houver plena suficiência e certeza de dimensões de dano e causalidade é que será possível definir a potencialidade do exercício individual na pretensão de reparação. Isso significa que durante o ciclo reativo, em que os vitimados se encontram em flagrante vulnerabilidade, não está a correr prazo prescricional, não há plena formação para que se tenha o contorno de actio nata.

Ainda aqui, na hipótese de ação coletiva para reparar dano em área que seja também privada, a possibilidade de absorção de efeitos acarreta consequências sobre a denominada subsistência do dano. ${ }^{20} \mathrm{~A}$ ação coletiva voltada para a reparação do dano é nesse ponto reconhecida como um despertar, como uma proclamação de efeitos difusos de que há pretensão de dano em reparação, afirmando uma situação de vulnerabilidade que se difunde socioambientalmente e viabiliza o exercício da postulação reparatória individual. Justamente pelo efeito difusor da pretensão reparatória ecológica, por seu caráter metaindividual, a ação coletiva irá impactar o exercício da ação voltada para tutela de direitos privados. A interligação entre direito ambiental e direito privado é procedida por meio de norma constante no Código de Proteção e Defesa do Consumidor.

A Lei n. 8.078/90 dispõe, em seu Título III, que as normas ali contidas se aplicam a todas as esferas de direitos difusos, abrangendo, portanto, o direito ambiental. A exegese é extraída do artigo 90 da Lei, quando remete à Lei da Ação Civil Pública. A partir de construção interpretativa, principalmente vinculada ao artigo 103 da Lei n. 8.078/90, pelo qual a pretensão coletiva provoca abertura de postulação individual pelos prejuízos insulares, formou-se argumentação no sentido de que a pretensão deduzida em ação coletiva é apta para produzir interrupção de prazo para o ajuizamento de ações individuais. Ao cabo, tem-se assim que o ajuizamento de ações coletivas voltadas para a tutela do bem ambiental ou ecológico provocam a interrupção de prazo prescricional para o ajuizamento de ações ligadas a danos ambientais individuais.

Essa base argumentativa foi assumida no julgamento do EREsp 1641167/RS ${ }^{21}$. O Superior Tribunal de Justiça veio a entender e categoricamente expor que o ajuizamento de ação civil pública interrompe o fluxo prescricional da ação privada voltada para reparação do dano

${ }^{20}$ STEIGLEDER, Annelise Monteiro. Responsabilidade civil ambiental..., p. 56.

${ }^{21}$ STJ. Terceira Turma. REsp n. 1641167/RS. Rel. Min. Nancy Andrighi. J. em 13 de março de 2018. DJ 20 de março de 2018.

Revista IBERC, Minas Gerais, v.2, n.1, p. 01-16, jan.-abr./2019 


\section{Revista IBERC}

v.2, n. 1, p. 01-16, jan.-abr./2019

www.responsabilidadecivil.org

individual coligado ao bem ambiental. A ocorrência do desastre ambiental de Brumadinho desencadeou diversas ações coletivas voltadas tanto para a tutela dos atingidos quanto para medidas reativas ao desastre e medidas de reparação. Em todas elas há algo em comum. A impossibilidade então existente de plenamente mensurar o dano em sua afetação tanto difusa quanto individual. A neblina judicante, e em especial o nível de vulnerabilidade que acomete as vítimas do desastre, impedem a fluência do termo inicial para o cômputo da prescrição de reparação dos danos individuais.

A articulação do direito ambiental com o direito civil, e ambos com o direito processual, é sustentada pelo Superior Tribunal de Justiça, o que revela claramente a adoção do diálogo de fontes na construção da solução jurídica, já que "não se pode olvidar também que, a partir do mesmo evento danoso, podem surgir pretensões coletivas, difusas e individuais, sejam homogêneas ou não, mesmo que tais pretensões sejam fundamentadas em diferentes ramos do direito" (REsp 1641167/RS).

Portanto, embora sujeito a prazo prescricional, as ações derivadas de dano ambiental individual possuem prazo de prescrição de três anos contados da plena configuração das dimensões de danos e causalidades que atingiram os vitimados, o que pode ser descortinado inclusive pelas ações coletivas que versem sobre o desastre. Nessa hipótese, a ação coletiva que demande e expresse a conformação do dano em sua dimensão global pode ser reconhecida como base para a actio nata individual, já que descortina a relação de lesão ao meio ambiente que reflete em direitos individuais.

\section{CONSIDERAÇÕES FINAIS}

A responsabilidade civil em matéria ambiental ainda é um tema em desenvolvimento. A maior parte das temáticas que a envolvem infiltram-se em abordagem interna a cada ramo jurídico, ainda dissociando o público e o privado na tematização do dano. É necessário ultrapassar a perspectiva de limites herméticos. Isso não significa dissolver limites e particularidades entre os ramos jurídicos, mas sim firmar que a confrontação da dinâmica prática exige uma interlocução normativa, exige um diálogo de fontes jurídicas de maneira a alcançar eficácia social correspondente às complexidades de uma sociedade de risco.

O dano ambiental individual não pode ser visto como dissociado do dano ambiental difuso. Relações jurídicas individuais estão envolvidas e incorporadas em um cenário amplo de interações em que o meio ambiente transpassa a linha do público e do privado, sedimentando-se em cada um desses prismas. Direito Ambiental e Direito Civil devem ser articulados de maneira 


\section{Revista IBERC}

v.2, n. 1, p. 01-16, jan.-abr./2019

www.responsabilidadecivil.org

inafastável, sob pena de se recair em simplismos e incorreções por visões parciais fragmentadas de um todo que se implica mutuamente. A titularidade do bem jurídico é fator alheio para a avaliação de lesões ambientais. A função ecológica e a integração de componentes dos processos ecológicos são o cerne que arregimenta os institutos de Direito Ambiental.

As demandas individuais para reparação de dano, quando fundadas em lesões a bens que Ihes são próprios, mas que também correspondam, parcial ou totalmente, com bens ambientais difusos, sofrem influxos diretos do regime jurídico ambiental, e inclusive do regime jurídico processual ambiental. Embora sujeitas à prescrição, ao contrário das ações de reparação de dano ambiental gestadas em caráter difuso, as ações voltadas para reparação de danos individuais, homogêneos ou puros, são diretamente influenciadas pelas ações coletivas.

Nessa linha, o desastre socioambiental de Brumadinho determina o diálogo das fontes para que na atenção aos danos e lesões sofridos pelos atingidos diretos e indiretos seja sempre considerada a dinâmica de responsabilidade, ônus da prova e princípios de causalidade inerentes ao direito ambiental. A responsabilidade a ser aplicada é a objetiva, pela teoria do risco integral.

Já o termo inicial para o marco prescricional de postulação de reparação de danos individuais ambientais será a superação da situação de crise e vulnerabilidade, com abertura de identificação plena da dimensão do dano e afetação de causalidade sobre o atingido. É assim impossível dissociar a actio nata de questões próprias da justiça ambiental, ${ }^{22}$ somente se podendo questionar de fluxo de prazo prescricional quando houver superação dos entraves decorrentes do desastre que vulnerabilizam os atingidos a ponto de lhes incapacitar para o pleno postular judicial. Esse marco pode ser estabelecido a partir da ação coletiva que expresse a conjuntura global do dano e do dever de reparação. Afinal, com a projeção difusa de sua postulação, pode-se revelar à coletividade de atingidos, ou mesmo ao atingido insular a conformação fático-jurídica da lesão sofrida.

\section{REFERÊNCIAS}

CARVALHO, Délton Winter de. Desastres ambientais e sua regulação jurídica: deveres de prevenção, resposta e compensação ambiental. São Paulo: Editora Revista dos Tribunais, 2015.

CARVALHO, Délton Winter de. Dano ambiental futuro: a responsabilização civil pelo risco ambiental. Porto Alegre: Livraria do Advogado, 2013.

\footnotetext{
${ }^{22}$ BIANCHI, Patrícia Nunes Lima. O papel da educação ambiental no âmbito da justiça ambiental no Brasil. In: SILVA, Antônio Wardison C. et al. Educação ambiental, étnico-racial e em direitos humanos: questões desafiadoras. São Paulo: Ed. Ideias e Letras; Unisal, 2018, p. 16.
} 
JAYME, Erik. Direito Internacional Privado e Cultura Pós-Moderna (1996). Cadernos do Programa de Pós-Graduação em Direito - PPGDir./UFRGS, Porto Alegre, v. 1, n. 1, nov. 2003. ISSN 2317-8558. Disponível em: http://seer.ufrgs.br/index.php/ppgdir/article/view/43487/27366. Acesso em: 01 ago. 2018. doi:https://doi.org/10.22456/2317-8558.43487.

LANCHOTTI, Andressa de Oliveira. Evaluación de impacto ambiental y desarrollo sostenible. Belo Horizonte: Arraes, 2014.

LEITE, José Rubens Morato; AYALA, Patrick de Araújo. Dano ambiental: do individual ao coletivo extrapatrimonial: teoria e prática. 5a Edição. São Paulo: Ed. Revista dos Tribunais, 2012.

METZGER, Jean Paul. O que é ecologia de paisagens? Biota Neotropica, Campinas/SP, vol. 1, n. 1/2, p. 1-9, 2001.

ODUM, Eugene P.; BARRET, Gary W. Fundamentos de ecologia. Trad. Pégasus Sistemas e Soluções. São Paulo: Cengage Learning, 2017. Título original: Fundamentals of ecology.

BIANCHI, Patrícia Nunes Lima. O papel da educação ambiental no âmbito da justiça ambiental no Brasil. In: SILVA, Antônio Wardison C., et al. Educação ambiental, étnico-racial e em direitos humanos: questões desafiadoras. São Paulo: Editora Ideias e Letras; Unisal, 2018.

RODRIGUES, Marcelo Abelha. Fundamentos da tutela coletiva. Brasília: Gazeta Jurídica, 2017.

ROSENVALD, Nelson. O direito civil em movimento: desafios contemporâneos. 2. ed. Salvador: Editora JusPodivm, 2018.

SIQUEIRA, Lyssandro Norton. Qual o valor do meio ambiente? Previsão normativa de parâmetros para a valoração econômica do bem natural impactado pela atividade minerária. Rio de Janeiro: Lumen Juris, 2017.

STEIGLEDER, Annelise Monteiro. Responsabilidade civil ambiental: as dimensões do dano ambiental no direito brasileiro. Porto Alegre: Livraria do Advogado Editora, 2017.

Recebido: 10.08 .2018

Aprovado: 10.02 .2019

Como citar: KOKKE, Marcelo. Responsabilidade civil e dano ambiental individual no desastre de Brumadinho. Revista IBERC, Minas Gerais, v. 2, n. 1, p. 01-15, jan.-abr./2019. 